\title{
Structural Inference and the Lucas Critique*
}

\author{
Fabrice Collard ${ }^{\dagger}$ \\ CNRS-GREMAQ and IDEI \\ Patrick Fève \\ Université de Toulouse I, GREMAQ and IDEI \\ François Langot ${ }^{\S}$ \\ Cepremap \& GAINS (U. du Maine) \\ First draft - January 2000 \\ This draft - March 2001
}

\begin{abstract}
We develop a structural model that aims at characterizing a set of restrictions allowing for a statistical evaluation of the effect of changes in monetary policy rules on aggregate dynamics at business cycle frequency. Standard econometric tools are first used to reveal and estimate changes in monetary policy rules over two sub-samples. We then test the ability of our model to match a set of moments summarizing the distribution of the data over the two sub-samples. We find that - holding the deep parameters of the model (preferences and technology) constant - monetary policy parameters adjust to match the data, therefore illustrating the empirical relevance of the Lucas critique.
\end{abstract}

Keywords: Lucas critique, monetary policy rules, method of moments, stability tests.

JEL classification: C51, C52, E32, E52

\footnotetext{
${ }^{*}$ We would like to thank D. Andolfatto, P. Beaudry, J.P. Benassy, A. Chéron, R. Farmer, J.P. Florens, S. Grégoir, P.Y. Hénin, E. Leeper, D. Lopez-Salido, P. N'Diaye, F. Portier and K. Wallis as well as the other participants to the conference "The Econometrics of Policy Evaluation" (Paris, January 10-12, 2000), T2M conference (Nanterre, 2000), the 2nd Toulouse seminar on Macroeconomics (Toulouse, september 2000) and the Econometric Workshop (Toulouse, January 2001) for helpful comments on a previous version. We are also thankful to two anonymous referees.

${ }^{\dagger} \mathrm{e}-\mathrm{mail}$ : fabrice.collard@univ-tlse1.fr

$\ddagger$--mail: patrick.feve@univ-tlse1.fr

§Corresponding author address: Cepremap, 142 rue du Chevaleret, 75013 Paris. Tel: (+33) 1-40-77-84-53 Fax: (+33) 1-44-24-38-57 e-mail: flangot@univ-lemans.fr
} 


\section{Introduction}

In his seminal paper, Lucas [1976] shows that traditional econometric evaluation of alternative economic policies is not robust. More precisely, he underlines that reduced forms in econometric studies do not constitute a coherent framework for evaluating policy changes implications.

"Given that the structure of an econometric model consist of optimal decision rules of economic agents, and that optimal decision rule vary systematically with change in the structure of series relevant of the decision maker, it follows that any change in policy will systematically alter the structure of econometric models" (Lucas [1976], p.40)

In others, quantitative evaluations of alternative economic policies based on reduced form do not provide any useful piece of information and may even be misleading.

However, based on the concept of super-exogeneity developed by Engle, Hendry and Richard [1983], a bunch of empirical studies have suggested that the Lucas critique may not be quantitatively important (see e.g. Ericsson and Irons [1995]). If we take this argument seriously, it follows that the Lucas critique is not "statistically" relevant and traditional econometric approaches to economic policies evaluations may still be robust, and worth pursuing. But, recent works (see e.g. Lindé [1999] among others) underline the lack of power of super exogeneity tests, which casts doubts on the statistical irrelevance of the Lucas critique. Another route is investigated by Estrella and Fuhrer [1999], who provide empirical evidence for greater stability of estimations based on backward-looking rather than on forward-looking models. This constitutes a paradox as if the Lucas critique were relevant, forward-looking models should yield more stable estimates. However, this approach encounters two major shortcomings: (i) it relies on ad-hoc models and reduced-forms and (ii) they often lead to models that are not supported by the data. Therefore, the lack of stability of forward-looking estimations cannot be attributed neither to the forward-looking characteristic of the model nor to its rejection by the data. Thus, the Lucas critique should be reevaluated from a statistical point of view.

In this paper, we follow another route suggested by Rotemberg and Woodford [1998] and rely on an econometric methodology that explicitly takes advantage of the restrictions imposed by general equilibrium, as

"Ultimately, it [demanding that one's structural relations be derived from individual optimization] is the only way in which the "observational equivalence" of a multitude of alternative possible structural interpretations of the co-movements of aggregate series can be resolved" (Rotemberg and Woodford [1998], p.1)

The estimating and testing strategy can be described as follows. We first look for potential break in the distribution of macroeconomic aggregates over the sample we consider. If two successive distributions are statistically different and given a set of structural parameters of the model, the economic policy 
(monetary policy in our case) rules can be estimated over each sub-sample in a second step. If the model is not rejected by the data over each sub-sample - and under the assumption that the deep parameters are held constant - an estimation of the relevant monetary policy rule can be obtained in each sub-sample. Finally, the stability of the estimated rules can then be tested. Rejection then supports the empirical relevance of the Lucas critique, as changes in the economic policy are sufficient to account for changes in the distribution of aggregates. Finally, an illustration of the quantitative relevance of the Lucas critique, may be obtained by computing impulse response functions of aggregates to shocks when the monetary policy rule is properly used and misused by the policy maker.

In this paper, we are interested in evaluating the stability of monetary policy rules. We develop a limited participation model à la Lucas [1990], where money is non-neutral as a fraction of the wage bill must be financed by borrowing cash on the credit market. ${ }^{1}$ Following Christiano and Gust [1999], we further assume that this fraction is an exogenous stochastic process, that can be viewed as a money demand shock on the labor market.

Monetary policy departs from the so-called Taylor rule (see Taylor [1993]) and assume that the instrument of the monetary policy is the rate of growth of money supply rather than the nominal interest rate $^{2}$. Money supply is assumed to respond to changes in lagged output gap and inflation rate.

The econometric methodology is based on a method of moments, that permits to estimate the parameters of the policy rule taking advantage of the information carried by the general equilibrium model. Roughly speaking, this method consists in choosing estimates for the policy parameters that yield the best match between empirical and theoretical moments. The main advantages of our approach can be found in (i) its ability to exploit all the model restrictions in order to estimate the parameters and (ii) to take into account the "moments uncertainty" for testing the model. In this context, if the parameters of the policy rule change — as suggested by a bunch of studies (see e.g. Clarida, Gali and Gertler [1998] or Judd and Rudebush [1998]) — the forward-looking behaviors followed by individuals imply that the parameters of model reduced-form do vary. Given the set of restrictions that allows to estimate the monetary policy rule parameters, we conduct an over-identification test in order to evaluate the ability of the model to match the data. If the model is not rejected by the data, the instability of monetary policy rule can then be checked. Our approach overcomes one drawback of Ireland's [1999] proposal, who does not test for the rejection of the model. Without this preliminary test, Ireland's results cannot be taken as being sufficiently informative as if the model is rejected by the

\footnotetext{
${ }^{1}$ See for quantitative evaluation of this type of model the papers of Christiano, Eichenbaum and Evans [1997], Christiano, Eichenbaum and Evans [1998] and Andolfatto and Gomme [1999].

${ }^{2}$ This choice is partly motivated by the fact that introduction of Taylor rule in dynamic general equilibrium models often leads to real indeterminacy (see Kim [1996], Kerr and King [1996], Rotemberg and Woodford [1998], Christiano and Gust [1999] or Collard [1999]).
} 
data, no useful information can be extracted from stability tests. Contrary to Ireland, our inference method allows to evaluate the quantitative relevance of the Lucas critique after this preliminary test.

Our results indicates that changes in monetary policy rule are sufficient to account for differences between moments estimated on the different sub-samples we consider. Finally, an impulse response function analysis furnishes an additional quantitative illustration of the empirical relevance of the Lucas critique.

The plan of the paper is as follows. Section 1 presents the model. Section 2 is devoted to the econometric methodology and empirical results. A last section offers some concluding remarks.

\section{The Theoretical Framework}

This section is devoted to the exposition of the model. In the lines of Lucas [1990], we set up a limited participation model that generates a liquidity effect, such that the model is in accordance with the common central bankers view on the nominal interest rate dynamics. The central assumption is that firms must borrow cash in advance from financial intermediaries to finance a fraction of the wage bill. Following Christiano and Gust [1999], this fraction is stochastic and represents a stochastic demand shock on the labor market. The households' behavior is first presented, then we describe the production plans of the firms. Finally, financial intermediaries and monetary policy are introduced.

\subsection{Households}

The economy is comprised of a unit mass continuum of identical infinitely lived agents. Each agent has preferences over random streams of consumption goods $\left(C_{1, t}\right.$ and $\left.C_{2, t}\right)$ and leisure $L_{t}$ represented by an expected utility function:

$$
E_{0} \sum_{t=0}^{\infty} \beta^{t} U\left(C_{1, t}, C_{2, t}, L_{t}\right) \text { with } 0<\beta<1
$$

where

$$
U\left(C_{1, t}, C_{2, t}, L_{t}\right)=\log \left(C_{1, t}\right)+\theta \log \left(C_{2, t}\right)+\gamma L_{t}
$$

In each and every period, each household is endowed with one unit of time per period, which she allocates between labor $\left(N_{t}\right)$ and leisure. She thus faces the constraint: $1=L_{t}+N_{t}$. At the beginning of the period $t$, money supply $M_{t}$ is held by households in the form of cash $\left(M_{t}^{c}\right)$ and deposits $\left(M_{t}^{d}\right)$, such that total money held by households is given by

$$
M_{t}=M_{t}^{c}+M_{t}^{d}
$$

$M_{t}^{c}$ can interpreted as money held in checking account that yield zero interest rate and $M_{t}^{d}$ as money held in saving accounts that yields a positive nominal interest rate $\left(R_{t}-1\right)>0$. The key assumption to generate a liquidity effect is that the choice of the composition money holdings is predetermined. 
A checking account is held by each household as cash is needed to purchase "cash" goods $C_{1, t}$, such that each household faces the following cash-in-advance constraint

$$
P_{t} C_{1, t} \leqslant M_{t}^{c}
$$

where $P_{t}$ is the aggregate price level.

The nominal income of households is composed of $(i)$ wage income $W_{t} N_{t}$, where $W_{t}$ denotes the nominal wage rate, $(i i)$ interest income associated to money deposits $\left(R_{t}-1\right) M_{t}^{d}$, and (iii) dividends from firms, $F_{t}$, and financial intermediaries, $B_{t}$. These revenues are then used to consume and get money for the next period. The intertemporal budget constraint then takes the form

$$
M_{t+1}^{c}+M_{t+1}^{d}=R_{t} M_{t}^{d}+W_{t} N_{t}+F_{t}+B_{t}-P_{t} C_{2, t}
$$

The problem of an household is then to choose her consumption-savings, labor and money holdings plans, $\left\{C_{1, t}, C_{2, t}, N_{t}, M_{t+1}^{c}, M_{t+1}^{d}\right\}_{t=0}^{\infty}$, to maximize (1) subject to (2)-(4), and given the stochastic processes for $\left\{P_{t}, W_{t}, R_{t}, F_{t}, B_{t}\right\}_{t=0}^{\infty}$ and the initial conditions $M_{0}^{c}, M_{0}^{d}>0$.

\section{$1.2 \quad$ Firms}

In each and every period, a final good, $Y_{t}$, is produced by perfectly competitive firms with capital $K_{t}$ and labor $N_{t}$ by means of a constant returns to scale production function:

$$
Y_{t}=A_{t} K_{t}^{\alpha} N_{t}^{1-\alpha}
$$

where $A_{t}$ is a technological shock, which is assumed to follow a stationary $\operatorname{AR}(1)$ process :

$$
\log \left(A_{t}\right)=\rho_{a} \log \left(A_{t-1}\right)+\left(1-\rho_{a}\right) \log (A)+\epsilon_{a, t}
$$

where $\epsilon_{a, t}$ is a centered i.i.d. process with variance $\sigma_{a}^{2}$ and where $\left|\rho_{a}\right|<1$.

The capital stock is owned by firms and labor is rented at the nominal wage $W_{t}$. It is assumed that firms borrow money from a financial intermediary at interest rate $R_{t}$ in order to finance a stochastic fraction $J_{t}$ of the total wage bill $W_{t} N_{t}$. The random variable $J_{t}$ is assumed to follow a stationary $\operatorname{AR}(1)$ process $^{3}$

$$
\log \left(J_{t}\right)=\rho_{J} \log \left(J_{t-1}\right)+\epsilon_{J, t}
$$

where $\epsilon_{J, t}$ is a centered i.i.d. process with variance $\sigma_{J}^{2}$ and where $\left|\rho_{J}\right|<1$.

After payment of interests to financial intermediaries, wage bill and capital expenditures, the dividends distributed at the household are

$$
F_{t}=P_{t} Y_{t}-R_{t} J_{t} W_{t} N_{t}-\left(1-J_{t}\right) W_{t} N_{t}-P_{t} I_{t}
$$

\footnotetext{
${ }^{3}$ Implicit in this specification is that $J_{t}$ is equal to one at the deterministic steady state. If $J_{t}>1$, the amount of liquidity contracted between employers and employees is greater than the wage bill. The surplus is then distributed as dividends.
} 
Capital accumulates according to the standard law of motion:

$$
K_{t+1}=(1-\delta) K_{t}+I_{t}
$$

where $I_{t}$ denotes investment and $\delta \in[0 ; 1]$ is the constant depreciation rate.

Firms choose the contingency plan $\left\{Y_{t}, N_{t}, I_{t}, K_{t+1}, P_{t}, F_{t}\right\}_{t=0}^{\infty}$ to maximize the expected discount value of the dividend flow

$$
E_{0} \sum_{t=0}^{\infty} \Phi_{t+1} F_{t}
$$

subject to the constraints (5)-(9)and given the stochastic processes for $\left\{P_{t}, W_{t}, R_{t}, \Phi_{t}, A_{t}, J_{t}\right\}_{t=0}^{\infty}$ and the initial condition for capital stock $K_{0} \geq 0$. As firms act in the best interest of the shareholders, the stochastic discount factor corresponds to the representative household's relative valuation of cash across time

$$
\Phi_{t+1}=\frac{\beta^{t+1}}{P_{t+1}} \frac{\partial U\left(C_{1, t+1}, C_{2, t+1}, L_{t+1}\right)}{\partial C_{1, t+1}}
$$

\subsection{Financial intermediaries}

At the beginning of period $t$, perfectly competitive financial intermediaries supply inelastically a quantity of money that originates from (i) the loanable founds provided by the households $M_{t}^{d}$ and (ii) a lump sum cash injection $X_{t}$ from the monetary authorities. Loan market clearing thus requires

$$
J_{t} W_{t} N_{t}=M_{t}^{d}+X_{t}
$$

At the end of the period, financial intermediaries have to repay the interests for the money loans by the households. Consequently, profit flows for the financial intermediaries are given by

$$
\begin{aligned}
B_{t} & =R_{t}\left(M_{t}^{d}+X_{t}\right)-\left(R_{t} M_{t}^{d}\right) \\
& =R_{t} X_{t}
\end{aligned}
$$

and are redistributed to households.

\subsection{Monetary Policy Rules}

Let $g_{t}-1$ denote the growth rate of the money supply. Then the money supply evolves as

$$
\begin{aligned}
M_{t+1} & =M_{t}+X_{t} \\
& \equiv g_{t} M_{t}
\end{aligned}
$$

where $M_{0}>0$ given.

The monetary authority conducts monetary policy by manipulating the rate of growth of money. The Federal Reserve behavior is thus summarized by the following specification

$$
\widehat{g}_{t}=\rho_{g} \widehat{g}_{t-1}+\left(1-\rho_{g}\right)\left(\pi_{y} \widehat{y}_{t-1}+\pi_{\pi} \widehat{\pi}_{t-1}\right)+\epsilon_{g, t}
$$


where $\epsilon_{g, t}$ is a centered i.i.d. process with variance $\sigma_{g}^{2}$ and $\left|\rho_{g}\right|<1$. This policy rule expresses the rate of growth of money supply, $\widehat{g}_{t}=\log \left(g_{t} / g\right)$, as a function of the output gap, $\widehat{y}_{t}=\log \left(y_{t} / y\right)$, and inflation in deviation from its target $\widehat{\pi}_{t}=\log \left(\pi_{t} / \pi\right)$.

Although the existence of unique equilibrium can not always be guaranteed when monetary policy is represented by the rule (11), one must check for determinacy from numerical analysis. Nevertheless, as our specification allows to manipulate the money supply, the model is more immune to real indeterminacy than models with a standard Taylor rule. ${ }^{4}$ This might be of importance as Farmer [1999] has shown that real indeterminacy implies that individual decision rules are left unaffected by changes in monetary policies as the model is then solved backward. The Lucas critique then becomes potentially inoperative. Conversely, as long as a unique equilibrium exists, any changes in monetary policy implies instability of the reduced form of the model. Then, any break in the monetary policy should reveal the quantitative relevance of the Lucas critique.

\section{Testing the Lucas Critique}

Given this structural model, we now investigate an econometric evaluation of the Lucas critique. Our strategy can be summarized as follows. Consider the simple representation of the log-linearized version of our model

$$
y_{t}=a E_{t} y_{t+1}+b x_{t} \text { where }|a|<1
$$

where $y_{t}$ and $x_{t}$ respectively denote the endogenous and the forcing variables. $x_{t}$ is assumed to follow a rule of the form

$$
x_{t}=\rho x_{t-1}+\sigma \varepsilon_{t} \text { with } \varepsilon_{t} i i d(0,1)
$$

The solution to this simple model is given by

$$
\left\{\begin{array}{l}
y_{t}=\frac{b}{1-a \rho} x_{t} \\
x_{t}=\rho x_{t-1}+\sigma \varepsilon_{t}
\end{array}\right.
$$

This reduced form may be used to estimate the parameters of the model and evaluate the empirical relevance of the Lucas critique. Our strategy then proceeds as follows

Step 1. Testing for the potential instability of the US monetary Business Cycle: We first estimate a set of moments that characterize the main features of observed fluctuations in the US economy. We then test for the instability of this set of moments and estimate the breakpoint. This leads us to select two sub-samples, whose characteristics differ significantly.

Step 2. Estimating and testing the structural model: We estimate the parameters of the policy rules holding the deep parameters constant ( $a=\bar{a}$ and $b=\bar{b}$ in our example) over the whole sample.

\footnotetext{
${ }^{4}$ Indeed, a bunch of studies has shown that introducing the Taylor type rule in optimizing agents-based model often leads to real indeterminacy (see Rotemberg and Woodford [1998], Christiano and Gust [1999], Collard [1999] or Carlstrom and Fuerst [2000]).
} 
This amounts to compute moments generated by the following reduced form

$$
\left\{\begin{aligned}
y_{t} & =\frac{\bar{b}}{1-\bar{\rho} \rho} x_{t} \\
x_{t} & =\rho x_{t-1}+\sigma \varepsilon_{t}
\end{aligned}\right.
$$

and therefore estimate $\sigma$ and $\rho$ to match the moments computed on actual data. As, we impose that the number of moments is greater than the number of parameters in the rule, we can conduct an overidentifying restriction test for each sub-sample.

Step 3. Testing for instability of the monetary policy rule: If the model is not rejected in each subsample, it is possible to evaluate the empirical relevance of the Lucas critique, inspecting the stability of the policy rule parameters.

Step 4. Illustrating the Lucas critique: In order to make our quantitative illustration more explicit, we go back to the simple model we developed at the beginning of the previous section (equations (12) and (13)). The structural model in sub-sample $i\left(M_{i}\right)$ is characterized by the following forward looking equation

$$
y_{t}=a E_{t} y_{t+1}+b x_{t} \text { where }|a|<1
$$

and the rule for the forcing variable $x$ in sub-sample $i\left(R_{i}\right)$ is given by

$$
x_{t}=\rho_{i} x_{t-1}+\sigma_{i} \varepsilon_{t} \text { with } \varepsilon_{t} i i d(0,1)
$$

The proper evaluation of the implication of rule $R_{j}$ in $M_{i}$ is to solve the model $M_{i}$ taken $R_{j}$ into account. Misusing $R_{i}$ then amounts to solve $M_{j}$ given $R_{j}$ and plugging $R_{i}$ in the model without solving $M_{j}$ again. This is summarized in table 1 . We apply this methodology to our

Table 1: The Lucas Critique at work

$$
\begin{array}{c|cc} 
& R_{1} & R_{2} \\
\hline M_{1} & \left\{\begin{array}{l}
y_{t}=\frac{b}{1-a \rho_{1}} x_{t} \\
x_{t}=\rho_{1} x_{t-1}+\sigma_{1} \varepsilon_{t}
\end{array}\right. & \left\{\begin{array}{l}
y_{t}=\frac{b}{1-a \rho_{1}} x_{t} \\
x_{t}=\rho_{2} x_{t-1}+\sigma_{2} \varepsilon_{t}
\end{array}\right. \\
M_{2} & \left\{\begin{array}{l}
y_{t}=\frac{b}{1-a \rho_{2}} x_{t} \\
x_{t}=\rho_{1} x_{t-1}+\sigma_{1} \varepsilon_{t}
\end{array}\right. & \left\{\begin{array}{l}
y_{t}=\frac{b}{1-a \rho_{2}} x_{t} \\
x_{t}=\rho_{2} x_{t-1}+\sigma_{2} \varepsilon_{t}
\end{array}\right.
\end{array}
$$

model and evaluate economic policy in the light of impulse response functions to a technological shock. In order to provide some metric to our evaluation, we compute the confidence interval for the well-specified model ( $M_{i}$ solved taken $R_{i}$ into account, $\left.\mathrm{i}=1,2\right)$.

The remaining of the section follows closely this approach.

\subsection{Is the US monetary business cycle unstable?}

As we are interested in the macroeconomic implications of a monetary rule in a small structural model, we choose a set of auxiliary parameters that the model aims at replicating. These auxiliary 
parameters are represented by a set of moments that characterize some key features of the US real and nominal business cycle. Following the approach developed by the NBER, the monetary business cycle is summarized by relative volatilities and correlations at leads and lags of output $(y)$, money growth $(g)$ and the gross nominal interest rate $(R)$ in the US economy. The empirical analysis is carried on quarterly data for the period 1959.Q4 $2 \quad$.Q3. ${ }^{5}$ The set of auxiliary parameters is therefore given by:

$$
\psi_{T}=\left\{\sigma_{y}, \sigma_{g}, \sigma_{R}, \rho(y, g(k)), \rho(y, R(k))\right\} \text { for } k=-1, \quad, 1
$$

Note that the information carried by these $q=9$ auxiliary parameters will be used to estimate the 4 unknown policy rule parameters $\theta$.

All variables are first logged and detrended using the Hodrick-Prescott filter. ${ }^{6}$ One may argue that the use of alternative filtering technique may enhance the power of the tests we will conduct next. However, this filter has the attractive feature of potentially eliminating permanent switches in the series we consider. It may be of importance, as the model we developed is not intended to capture such phenomena. Indeed, we are not interested in modelling permanent changes in the level and/or trend of the series but rather evaluate the influence of permanent changes in monetary policy rules on economic fluctuations. Hence changes in the monetary policy rules are assumed, in this study, to affect solely the cyclical components of the data, without it feeds back on their trend component. ${ }^{7}$

Two approaches may then be investigated when locating break points in the processes of aggregates. The first one, widely used in the literature that proposes estimates of monetary rules (see e.g. Clarida et al. [1998] or Judd and Rudebush [1998] among others), would amount to split the sample according to the chairman of the Fed: the terms of Arthur Burns (197 .Q1-1978.Q1), Paul Volcker (1979.Q31987.Q2) and Alan Greenspan (1979.Q3-Present). Another route we pursue is to adopt an agnostic view of the problem and to identify the potential breaking points relying on a statistical approach. We therefore consider Wald, Lagrange multiplier (LM) and likelihood ratio (LR) type tests for parameter instability and structural change with unknown change points proposed by Andrews [1993]. This approach then furnishes an estimate of the change poi 
Figure 1: Structural break test

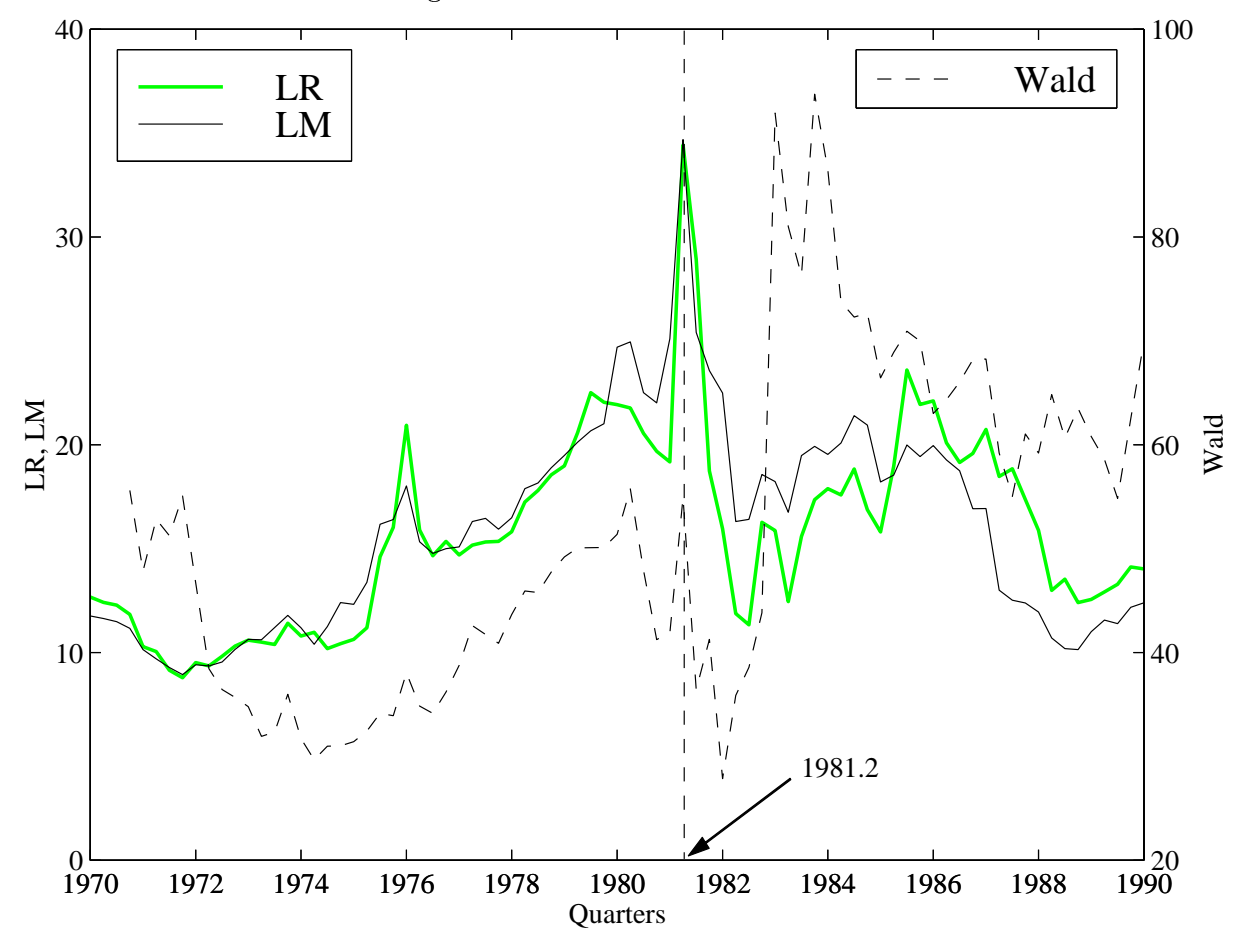

of the statistics is pretty smooth up to the end of the seventies and reaches a peak in early eighties, as witnessed by the sup value of LR and LM in table 2. Both LR and LM tests leads to select the second quarter of 1981 as a significant breaking point in the US monetary business cycle. Following 1981.Q2, LR and LM statistics sharply decrease and dampen. The Wald statistics would lead to

Table 2: Structural change tests

\begin{tabular}{lcccccc}
\hline \hline Test & Stat. & \% of sample & $10 \%$ & $5 \%$ & $1 \%$ & Breaking point \\
\hline Sup(LM) & 34.4272 & 0.5183 & 16.7695 & 19.1972 & 23.7182 & $1981: 2$ \\
Sup(LR) & 34.6878 & 0.5183 & 16.7695 & 19.1972 & 23.7182 & $1981: 2$ \\
Sup(Wald) & 93.7499 & 0.5793 & 19.0418 & 21.5728 & 26.2464 & $1983: 4$ \\
\hline \hline
\end{tabular}

select the last quarter of 1983 as a breaking point. However, the Wald statistics always lies above its critical value, whatever the time of change we consider. This illustrates problems of Wald tests in small sample, which leads to over-reject the null hypothesis. This led us to prefer LR and LM's diagnostic and therefore select 1981.Q2 as the change point. It is worth noting that this break point does not exactly fits the change in the FED's policy and the arrival of P. Volcker in 1979.Q3. One potential explanation for this result may be found in either delays in the implementation of the new monetary policy. Also note that this result is close to the conclusions of preceding empirical studies that aims at estimating the behavior of the US monetary authorities (see e.g. Clarida et al. [1998], Judd and Rudebush [1998], Estrella and Fuhrer [1999] among others). 
Table 3 reports the estimated moments on each sub-sample. Several striking features emerge from this table. First of all, output volatility decreases by about $20 \%$ between the two sub-samples while that of money growth doubles. In the same time the volatility of the nominal interest rate has remained steady. Figure 2, which reports the behavior of each series over the whole sample, illustrates this point as is appears that following 1981.Q2 (dashed line) the fluctuations in output around its trend dampen whereas money growth displays much more amplitude. This suggests that money may have been used as a buffer in the second sub-sample in order to maintain the nominal interest rate peg.

Table 3: Moments on US Data

\begin{tabular}{lcc}
\hline \hline & $\begin{array}{c}\text { First sub-sample } \\
(1959.4-1981.2)\end{array}$ & $\begin{array}{c}\text { Second sub-sample } \\
(1981.3-2000.3)\end{array}$ \\
\hline$\sigma_{y}$ & 1.6252 & 1.3588 \\
& $(0.2313)$ & $(0.4334)$ \\
$\sigma_{g}$ & 0.6656 & 1.2248 \\
& $(0.0561)$ & $(0.0826)$ \\
$\sigma_{R}$ & 0.3720 & 0.3455 \\
& $(0.0736)$ & $(0.0348)$ \\
$\rho(y, g(-1))$ & 0.2950 & -0.0733 \\
& $(0.1105)$ & $(0.1253)$ \\
$\rho(y, g)$ & 0.1851 & -0.0995 \\
& $(0.1167)$ & $(0.1393)$ \\
$\rho(y, g(+1))$ & 0.0419 & -0.2201 \\
& $(0.1101)$ & $(0.1230)$ \\
$\rho(y, R(-1))$ & 0.0640 & 0.2858 \\
$\rho(y, R)$ & $(0.2102)$ & $(0.2234)$ \\
$\rho(y, R(+1))$ & 0.3455 & 0.5132 \\
& $(0.1734)$ & $(0.2113)$ \\
\hline \hline
\end{tabular}

Note : Moments are obtained minimizing $Q_{T}$. Estimates are robust to both heteroskedasticity and serial correlation. We used a VARHAC(1) estimator.

A second striking feature that estimated moments exhibit lies in the inversion of the correlation of money growth and output at different leads and lags. Over the first sub-sample, these correlations were positive and only significant at one lag. A totally different pattern is found over the second sub-sample, as these correlations are negative and weakly significant at one lead. There is therefore an inversion in the pattern of the cross-correlogram. Finally, it appears that the correlation between output and the nominal interest rate has strengthened over the last sub-sample, as the instantaneous correlation has increased by almost $45 \%$ between the first and the second sub-sample. Simple algebra shows that half of this change is attributable to the change in the volatility of output, the remaining part results from a modification in the co-movement of output and nominal interest rate. 
Figure 2: Actual data (HP-filtered)
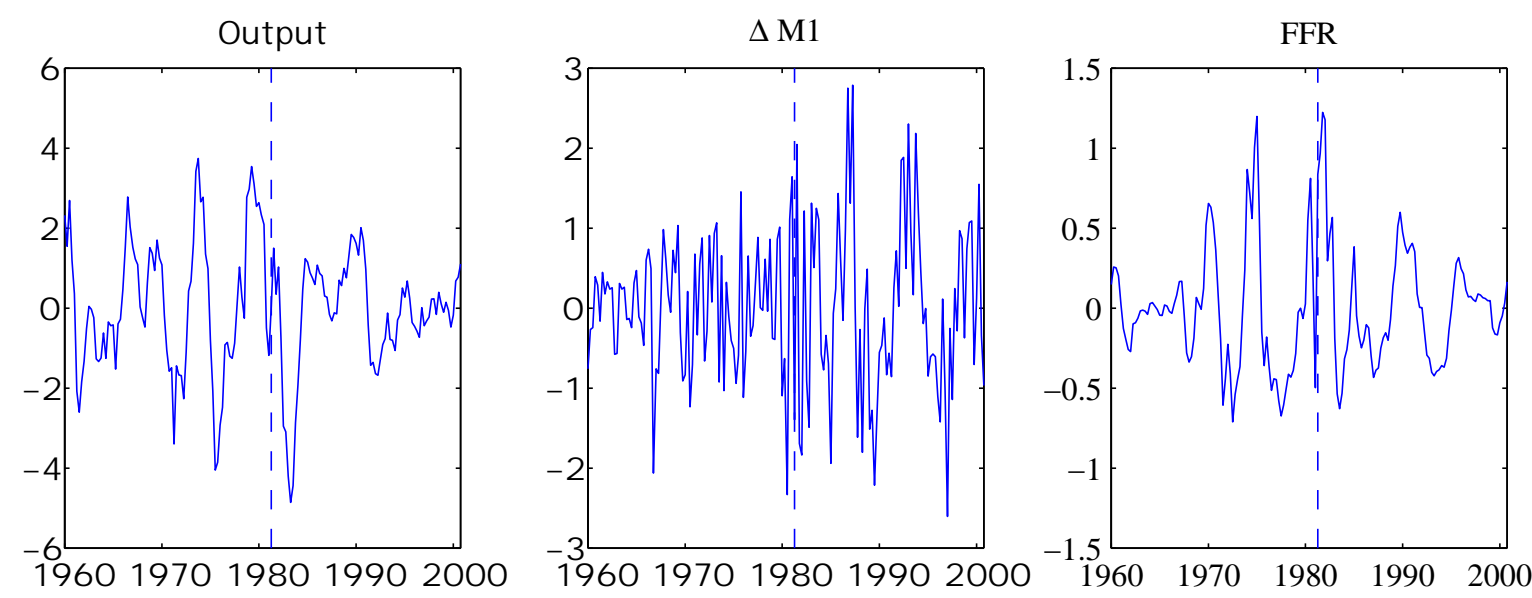

\subsection{Monetary policy rules}

This section is devoted to the estimation procedure used to obtain estimates for the parameters of the policy rule:

$$
\theta=\left\{\sigma_{g}, \rho_{g}, \pi_{y}, \pi_{\pi}\right\}
$$

where $\operatorname{dim}(\theta)=4$. This estimation is conducted under the restriction that the other structural parameters that reflect tastes and technology remain constant over the whole sample. The calibration is reported in table 4 . The discount factor, $\beta$, is set such that household values the future at an annual rate of $3 \%$. The weight associated to leisure in the utility function, $\gamma$, is set such that a given household devotes $31 \%$ of its total time endowment to productive activities. Following Cooley and Hansen [1995], the relative weight of credit goods in the utility function, $\theta$, is set such that the household purchases $84 \%$ of her total consumption in cash goods. The average rate of growth of money stances is set to its empirical counterpart, $\omega-1=1.30 \%$ per quarter over the whole sample. ${ }^{9}$

Table 4: Calibrated parameters

\begin{tabular}{cccccc}
\hline \hline$\beta$ & $h^{\star}$ & $c_{1}^{\star} / c^{\star}$ & $\alpha$ & $\delta$ & $\bar{g}$ \\
0.9926 & 0.31 & 0.84 & 0.10 & 0.0125 & 1.013 \\
\hline$\rho_{a}$ & $\sigma_{a}$ & $\rho_{J}$ & $\sigma_{J}$ & $J$ & \\
0.95 & 0.0079 & 0.95 & 0.0079 & 1 & \\
\hline \hline
\end{tabular}

On the technological side, $\alpha$ is set such that the model replicates the labor share $(60 \%)$. The depreciation rate, $\delta$, is set such that the annual depreciation rate is $5 \%$. The technology shock is

\footnotetext{
${ }^{9}$ We chose not to estimate the rate of growth of money, as in this model - and more generally in this class of models - money growth exerts a tiny effect on the quantitative properties of the economy. In fact, only humongous and unreasonable modifications in $\omega$ may exert a significant effect on the model properties. For instance, when we estimate $\omega$ over the two sub-samples, only a slight improvement in the objective function is found in the first sub-sample for an estimated value of $\omega$ implying a $21.5 \%$ money growth rate per quarter! In the second sub-sample, no significant improvement was found.
} 
calibrated according to Cooley and Prescott's [1995] estimates, such that $\rho_{a}=0.95$ and $\sigma_{a}=0.0079$. The persistence of the money demand shock, $J_{t}$, is arbitrarily set to $\rho_{J}=\rho_{a}$ and $\sigma_{J}=\sigma_{a}$ following Christiano and Gust [1999].

Endowed with the calibration, we estimate the parameters of the policy rule by a method of moments, which minimizes the discrepancy between moments generated by the theoretical model and their empirical counterpart. This essentially amounts to minimize the following loss function over each sub-sample $h=1,2$ :

$$
J_{h}\left(\theta_{h}\right)=f_{h}\left(\theta_{h}\right)^{\prime} W_{h} f_{h}\left(\theta_{h}\right)
$$

where $W_{h}$ is a definite-positive weighting matrix ${ }^{10}$ and

$$
f_{h}\left(\theta_{h}\right)=\left[\begin{array}{c}
\sigma_{y}\left(\theta_{h}\right)-\sigma_{y, h} \\
\sigma_{g}\left(\theta_{h}\right)-\sigma_{g, h} \\
\sigma_{R}\left(\theta_{h}\right)-\sigma_{R, h} \\
\rho(y, g(k))\left(\theta_{h}\right)-\rho_{h}(y, g(k)) \\
\rho(y, R(k))\left(\theta_{h}\right)-\rho_{h}(y, R(k))
\end{array}\right] \text { with }\left\{\begin{array}{l}
k=-1,0,1 \\
h=1,2
\end{array}\right.
$$

The direct reference to $\theta_{h}$ indicates that the corresponding moment is obtained from HP-filtered data generated by the model for the vector of policy parameters $\theta_{h}$. Necessary identifying conditions impose that the number of moments to be greater or equal to the number of parameters in the rule. Thus, one may conduct a global specification test, denoted $J-s t_{h h}=T_{h} J_{h}\left(\theta_{h}\right)$ at convergence. This statistic is asymptotically distributed as a chi-square, with $5=q-\operatorname{dim}(\theta)$ degrees of freedom.

Estimates of policy rule parameters are reported in table 5. We check during the estimation procedure for the saddle path property of the model, given the calibrated and estimated parameters. Numerical experiments reveal that unique equilibrium exists during the convergence of the numerical algorithm.

First of all, the model is supported by the data over the two sub-samples at the conventional significance level of $5 \%$. Thus our modelling choice that attempts to account for nominal fluctuations solely by means of a simple monetary rule appears to be relevant.

Over the first sub-sample, only the standard deviation of the discretionary shock and the output gap parameter are significant, such that the rule may reduce to the simple:

$$
\widehat{g}_{t}=f_{y} \widehat{y}_{t-1}+\varepsilon_{\gamma, t}
$$

Then, if we were to consider this policy rule, the model would still pass the over-identification test, as the J-stat would be of 5.82, with an associated p-value of $56 \%$ (the number of degrees of freedom is then equal to 7 ). The estimated parameter would be $f_{y}=0.0638$, with a standard deviation of 0.0219 , and $\sigma_{g}=0.0065$ with a standard deviation of 0.0005 . Hence, $\left(f_{y}, \sigma_{\gamma}\right)$ would not statistically differ from $\left(\pi_{y}, \sigma_{g}\right)$. This rule is consistent with the conventional wisdom that within the late sixties and the

\footnotetext{
${ }^{10}$ This matrix is given by the inverse of the covariance matrix of the moments, obtained from actual data. A consistent estimate for this matrix is obtained using a VARHAC estimator proposed by den Haan and Levin [1997]
} 
Table 5: Policy rule estimates

\begin{tabular}{lcc}
\hline \hline & $\begin{array}{c}\text { First sub-sample } \\
(1959.4-1981.2)\end{array}$ & $\begin{array}{c}\text { Second sub-sample } \\
(1981.3-2000.2)\end{array}$ \\
\hline$\sigma_{g}$ & 0.0067 & 0.0108 \\
& $(0.0006)$ & $(0.0010)$ \\
$\rho_{g}$ & 0.3310 & 0.3021 \\
& $(0.7909)$ & $(0.0686)$ \\
$\pi_{\pi}$ & -0.0353 & 0.3157 \\
& $(0.6029)$ & $(0.0651)$ \\
$\pi_{y}$ & 0.0724 & 0.0615 \\
& $(0.0318)$ & $(0.0363)$ \\
\hline J-stat & 3.4690 & 1.5104 \\
& {$[62.81]$} & {$[91.18]$} \\
\hline \hline
\end{tabular}

seventies, the FED conducted a policy that aimed at stabilizing mainly output fluctuations. Indeed, it may seems at a first glance that this rule yields an accommodating behavior from the monetary authorities as $\pi_{y}>0$, but this is not the case. Indeed, consider the case of a technology shock which accounts for $95 \%$ of output volatility in the short-run ${ }^{11}$ - that hits the economy in period $t$. In period $t$ the central bank does not react, but it is known to the the agents that in the next period, it will raise its money growth rate and therefore will create an inflation tax. The individuals instantaneously reduce their consumption and increase their leisure in order to avoid the inflation tax. Therefore, output responds to a lesser extent than it would have done if the rule were absent. Hence, the rule is stabilizing, as it acts as a built-in stabilizer through the inflation tax it creates.

Over the second sub-sample, both $\pi_{\pi}$ and $\pi_{y}$ are significant and positive. If $\pi_{y}$ still reveals the willingness of the central bank to smooth fluctuations, as it was the case over the first sub-sample, the positivity of $\pi_{\pi}$ is clearly destabilizing. However, this actually reflects the existence of a Taylor rule over the second sub-sample. Money just accommodates fluctuations in the nominal interest rate, which attempts to stabilize the economy. Indeed, if the central bank decides, as it is claimed by the FED to fix the nominal interest rate in reaction to (expected) output and inflation changes, the money supply is used to clear the money market and must therefore accommodate economic fluctuations, as witnessed by the increase in the money supply growth volatility. Another way to illustrate this feature is to acknowledge the large increase in $\sigma_{g}$ which raised by $60 \%$ between the first and the second sub-sample.

Table 6 reports the actual moments and the moments generated by our theoretical model. It first appears, as already indicated by the over-identification test that all moments are pretty well reproduced by the model. It is noteworthy that the model performs particularly well in terms of volatility. The model tends to overestimate the instantaneous correlation between money growth and output and between output and the nominal interest rate over the first sub-sample, but this

\footnotetext{
${ }^{11}$ This was obtained from the variance decomposition of output generated by the model using estimated rules.
} 
Table 6: Moment Implications

\begin{tabular}{lcccc}
\hline \hline & \multicolumn{2}{c}{$\begin{array}{c}\text { First sub-sample } \\
(1959.4-1981.2)\end{array}$} & \multicolumn{2}{c}{ Second sub-sample } \\
& $(1981.3-2000.2)$ \\
\hline & Actual & Model & Actual & Model \\
\hline$\sigma_{y}$ & 1.6252 & 1.7137 & 1.3588 & 1.7592 \\
$\sigma_{g}$ & 0.6656 & 0.6667 & 1.2248 & 1.2391 \\
$\sigma_{R}$ & 0.3720 & 0.4070 & 0.3455 & 0.3582 \\
$\rho(y, g(-1))$ & 0.2950 & 0.2026 & -0.0733 & 0.0510 \\
$\rho(y, g)$ & 0.1851 & 0.2692 & -0.0995 & -0.0234 \\
$\rho(y, g(+1))$ & 0.0419 & 0.0353 & -0.2201 & -0.1656 \\
$\rho(y, R(-1))$ & 0.0640 & 0.1348 & 0.2858 & 0.2645 \\
$\rho(y, R)$ & 0.3455 & 0.4947 & 0.5132 & 0.5043 \\
$\rho(y, R(+1))$ & 0.5618 & 0.5976 & 0.6115 & 0.5567 \\
\hline \hline
\end{tabular}

overestimation is not statistically significant. ${ }^{12}$

\subsection{Stability of the monetary policy rules}

In order to gauge the relevance of the Lucas critique, and given that the model is not rejected by the data over the two sub-sample, we now evaluate the stability of the monetary policy rules over the two sub-samples. When the stability of the monetary policy rules is not supported by the data, then this indicates that the instability in the monetary business cycle can potentially be accounted for by changes in the policy rule - provided all other aspects of the model have stayed the same. Indeed, as shown by Hall and Sen [1999], instability in GMM estimates may stem from a pure change in parameter values and/or a change in the structure of the model, the latter revealing a model specification problem. It is therefore important to test the validity of overidentifying restrictions before and after the breakpoint. Hall and Sen [1999] show that the test statistic is given by the sum of the overidentifying restriction tests for each sub-sample, which is distributed as a chi-square with 10 degrees of freedom in our case. The value of the statistics is 4.9794 with an associated p-value of $89.25 \%$, which yields not to reject the stability of overidentifying restrictions over the two sub-samples. Hence, any source of instability can be found in changes in monetary policy rules.

Table 7 reports global and partial instability LR, LM and Wald tests for the policy rule parameters. Pure structural stability of the rules is strongly rejected whatever the considered statistics. Hence, the Lucas critique is valid, as significant changes in the US monetary business cycle can be explained solely by a significant change in the US monetary policy. Partial stability tests help understanding the source of this result. As can be seen from table 7, instability mainly comes from changes in the volatility of money injections. This actually reveals a deep change in FED's practices in the conduct of monetary policy, and actually identifies the switch to a Taylor type rule. Indeed, as illustrated in

\footnotetext{
${ }^{12}$ A simple test of equality between the actual and the predicted moments does not leads to the rejection of the null hypothesis at the $5 \%$ significance level.
} 
Table 7: Stability tests for Policy rules estimates

\begin{tabular}{lccc}
\hline \hline & LM & LR & Wald \\
\hline$\sigma_{g}$ & 6.1429 & 12.0507 & 6.3994 \\
& {$[1.32]$} & {$[0.05]$} & {$[1.14]$} \\
$\rho_{g}$ & 0.0002 & 0.0002 & 0.0037 \\
& {$[98.87]$} & {$[98.88]$} & {$[95.15]$} \\
$\pi_{\pi}$ & 0.1520 & 3.1884 & 4.1577 \\
& {$[69.66]$} & {$[7.42]$} & {$[4.14]$} \\
$\pi_{y}$ & 0.3828 & 0.0225 & 0.0229 \\
& {$[53.61]$} & {$[88.08]$} & {$[87.97]$} \\
\hline Global & 33.7684 & 39.7108 & 28.0403 \\
& {$[0.00]$} & {$[0.00]$} & {$[0.00]$} \\
\hline \hline
\end{tabular}

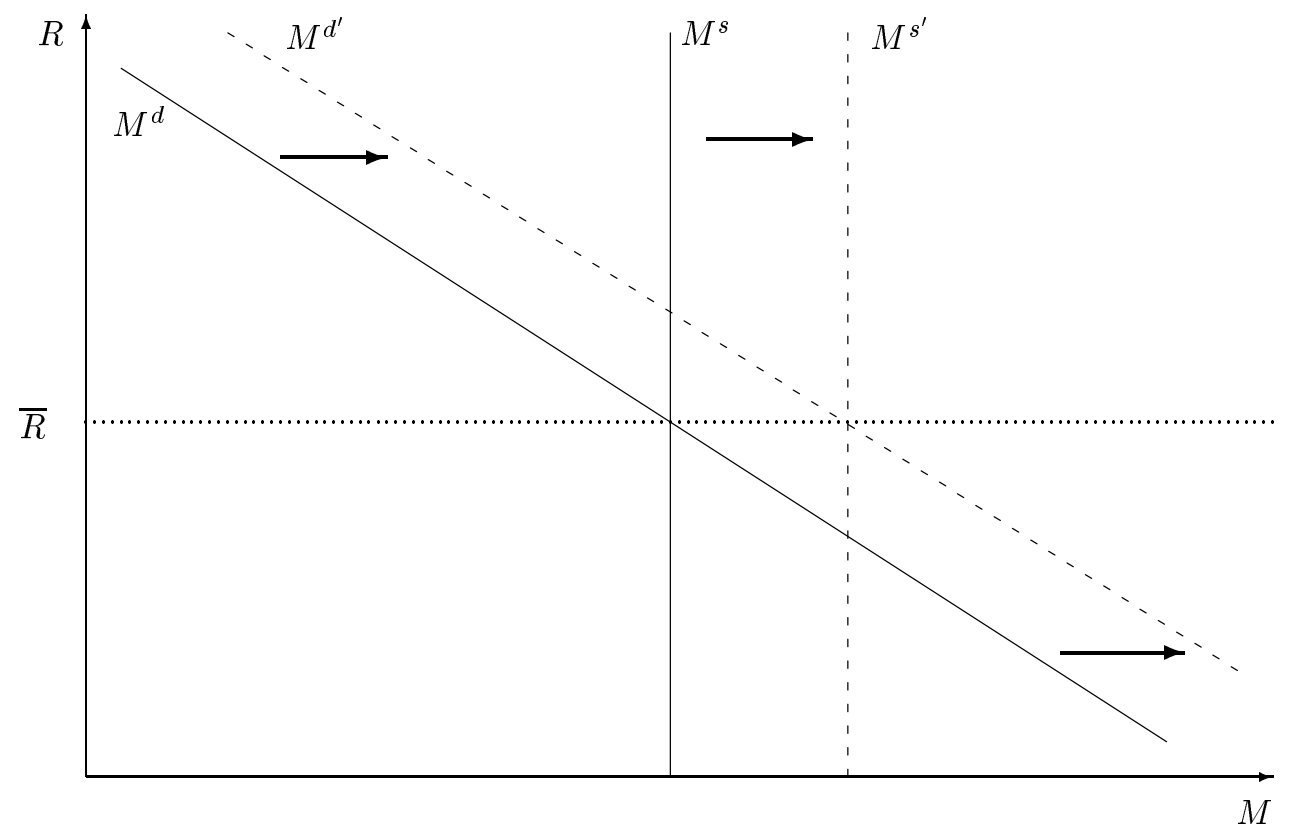

Figure 3: Money market clearing 
figure 3, when the FED sets the nominal interest rate $(R=\bar{R})$, money injections $\left(M^{s}\right)$ are essentially used to clear the money market (shift from $M^{s}$ to $M^{s^{\prime}}$ ). Money then acts as a buffer, and therefore exhibits much more volatility.

\subsection{The Lucas Critique at work}

In order to illustrate the Lucas critique, we report impulse response functions to a technological shock when the monetary policy rule is properly used and misused by the policymaker. ${ }^{13}$

This illustration is performed taking parameter uncertainty into account. Figure 4 reports the impulse response functions of output, the inflation rate, nominal interest rate and money growth to a one percent positive technological shock for the first sub-sample. The thick grey line corresponds to the IRF when $M_{1}$ is solved with $R_{1}$, dashed line are the confidence intervals at the $95 \%$ level and the plain dark line corresponds to the IRF when $R_{1}$ is plugged in the $M_{2}$ solved using $R_{2}$. The responses are conform to a standard technological shock. Output and nominal interest rate rises above their steady state value and inflation drops. Money growth rises, according to the monetary policy rule. The misuse of $R_{1}$ in $M_{2}$ yields clear cuts. The response of output is significantly overestimated in the very short-run while the inflation drop is overestimated. Conversely, the nominal interest rate response is underestimated. Money growth lies within the confidence interval, since most of the changes are found in the volatility rather in policy rule multipliers. More interestingly, the inflation rate appears to be mis-evaluated over the whole path, as it lies out of confidence interval at each horizon. This last result illustrates that the Lucas critique fully plays.

As far as $R_{2}$ is concerned, the Lucas critique also significantly applies as can be seen from the lower panel of figure 4 . The main difference is found in the inversion of the evaluation errors, as the rise in nominal interest rate is overestimated whereas the inflation drop and the output upward shift are underestimated.

\section{Concluding remarks}

This paper develops a small structural model that attempts to account for the nominal properties of the business cycle, relying on a simple monetary rule. Holding the deep parameters on preferences and technology constant, we estimate the rule by means of a method of moments. We then show that instability of the monetary policy rule is sufficient by itself to account for changes in the observed nominal business cycle, as no significant change in the overidentifying restrictions can be found. This illustrate how structural models can be used to estimate and test for stability of monetary policy rule, conditionally on fully specified forward-looking money demand. Finally, the exercise underlines the quantitative relevance of the Lucas critique.

\footnotetext{
${ }^{13}$ We restrict our attention to a technological shock for room purposes, but results for the other shocks leads to very similar conclusions and do not alter the main findings. They are available from the authors upon request.
} 
Figure 4: Technological shock

Rule 1
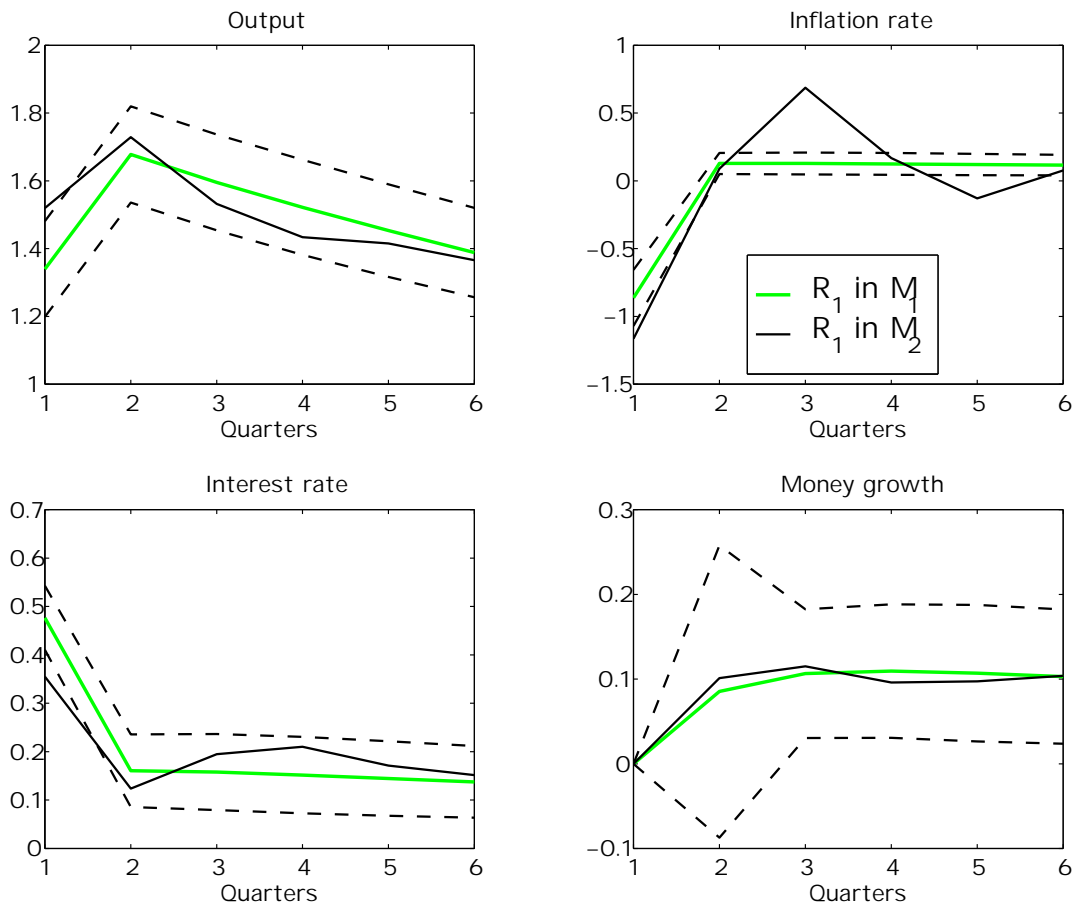

Rule 2
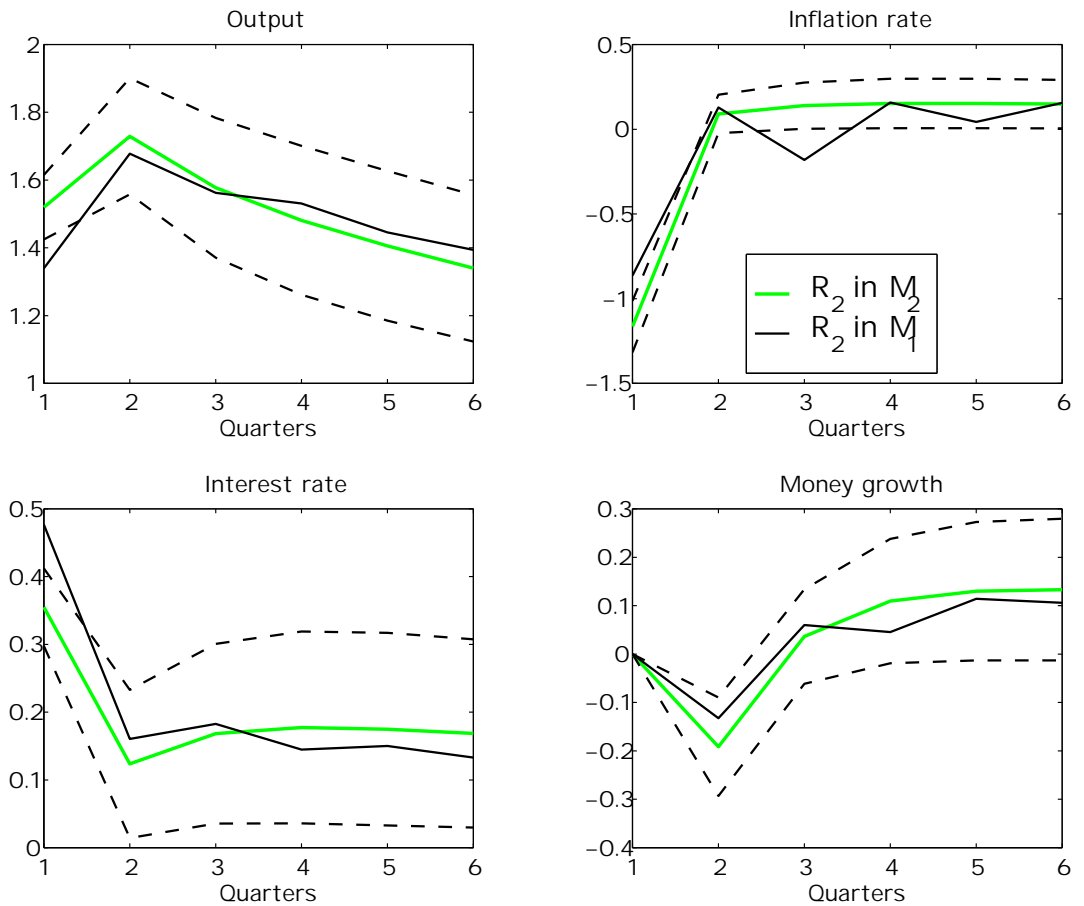


\section{References}

Andolfatto, D. and Gomme, P. , 1999, Monetary policy regimes and beliefs, Working Paper 99-05, Federal Reserve Bank of Cleveland, Cleveland (OH).

Andrews, D. , 1993, Tests for parameter instability and structural change with unknown change point, Econometrica 61(4), 821-856.

Carlstrom, C. and Fuerst, T. , 2000, Forward-looking versus backward-looking taylor rules, Working Paper 0009, Federal Reserve Bank of Cleveland.

Christiano, L. and Gust, C. , 1999, Taylor rules in a limited participation model, Working Paper 7017, NBER, Cambridge (MA).

Christiano, L., Eichenbaum, M. and Evans, C. , 1997, Sticky price and limited participation models of money: A comparison, European Economic Review 41, 1201-1249.

Christiano, L., Eichenbaum, M. and Evans, C. , 1998, Modeling money, Working Paper 6371, NBER.

Clarida, R., Gali, J. and Gertler, M., 1998, Monetary policy rules and macroeconomic stability: Evidence and some theory, Working Paper 98-01, C.V. Starr Center for Applied Economics, New-York (NY).

Collard, F. , 1999, Monetary policy and economic fluctuations, miméo, Cepremap.

Cooley, T. and Hansen, G., 1995, Money and the business cycle, in T. Cooley, ed., 'Frontiers of Business Cycle Research', Princeton University Press, Princeton, New-Jersey, chapter 7.

den Haan, W. and Levin, A. , 1997, A practioner's guide to robust covariance matrix estimation, in G. Maddala and C. Rao, eds, 'Handbook of Statistics: Robust Inference', Vol. 15, Elsevier, New-York, chapter 12.

Engle, R., Hendry, D. and Richard, J. , 1983, Exogeneity, Econometrica 51(2), 277-304.

Ericsson, N. and Irons, J. , 1995, The lucas critique in practice: Theory without measurement, in K. Hoover, ed., 'Macroeconometrics: Developments, Tensions and Problems', Kluwer Academics Plublisher, Boston (MA), chapter 8.

Estrella, A. and Fuhrer, J. , 1999, Are "deep" parameters stable? the lucas critique as an empirical hypothesis, Working Paper 99-4, Federal Reserve Bank of Boston, Boston (MA).

Farmer, R. , 1999, Why does data reject the lucas critique?, miméo, IUE.

Hall, A. and Sen, A. , 1999, Structural stability testing in models estimated by generalized method of moments, Journal of Business Economics and Statistics 17(3), 335-348. 
Judd, J. and Rudebush, G. , 1998, Taylor's rule and the fed: 1970-1997, Federal Reserve Bank of San Francisco Economic Review 3, 3-16.

Kerr, W. and King, R. , 1996, Limits on interest rules in the is model, Federal Reserve Bank of Richmond Economic Quarterly 82(2), 47-75.

Kim, J. , 1996, Monetary policy in a stochastic equilibrium model with real and nominal rigidities, mimeo, Yale University.

Lindé, J., 1999, Testing for the lucas critique: A quantitative investigation, miméo, Stockholm School of Economics.

Lucas, R. , 1976, Econometric policy evaluation: A critique, Carnegie Rochester Conference Series on Public Policy 1, 19-46.

Lucas, R. , 1990, Liquidity and interest rates, Journal of Economic Theory 50, 237-64.

Rotemberg, J. and Woodford, M. , 1998, Interest-rate rules in an estimated sticky price model, Working Paper 6618, NBER.

Taylor, J. , 1993, Discretion versus policy rules in practice, Carnegie Rochester Conference Series on Public Policy 39, 195-214. 


\section{A Solving the Model}

\section{A.1 Households Program}

Let $\Omega_{t}$ denote the aggregate state vector, so that $\left\{M_{t}^{c}, M_{t}^{d}, \Omega_{t}\right\}$ is the state vector for the representative household. Let $\mathcal{V}\left(M_{t}^{c}, M_{t}^{d}, \Omega_{t}\right)$ be the maximal utility. $\mathcal{V}$ must satisfy the following recursive relationship where $\mathcal{C}_{t}=\left\{C_{1, t}, C_{2, t}, N_{t}, M_{t+1}^{c}, M_{t+1}^{d}\right\}$ :

$$
\begin{aligned}
\mathcal{V}\left(M_{t}^{c}, M_{t}^{d}, \Omega_{t}\right)= & \max _{\mathcal{C}_{t}}\left\{U\left(C_{1, t}, C_{2, t}, N_{t}\right)+\beta E_{t} \mathcal{V}\left(M_{t+1}^{c}, M_{t+1}^{d}, \Omega_{t+1}\right)\right. \\
& +\lambda_{1, t}\left[R_{t} M_{t}^{d}+W_{t} N_{t}+F_{t}+B_{t}-P_{t} C_{2, t}-M_{t+1}^{c}-M_{t+1}^{d}\right] \\
& \left.+\lambda_{2, t}\left[M_{t}^{c}-P_{t} C_{1, t}\right]\right\}
\end{aligned}
$$

First order conditions for an interior solution are:

$$
\begin{aligned}
U_{1}\left(C_{1, t}, C_{2, t}, N_{t}\right) & =P_{t} \lambda_{2, t} \\
U_{2}\left(C_{1, t}, C_{2, t}, N_{t}\right) & =P_{t} \lambda_{1, t} \\
U_{3}\left(C_{1, t}, C_{2, t}, N_{t}\right) & =W_{t} \lambda_{1, t} \\
\beta E_{t} \mathcal{V}_{1}\left(M_{t+1}^{c}, M_{t+1}^{d}, \Omega_{t+1}\right) & =\lambda_{1, t} \\
\beta E_{t} \mathcal{V}_{2}\left(M_{t+1}^{c}, M_{t+1}^{d}, \Omega_{t+1}\right) & =\lambda_{1, t}
\end{aligned}
$$

The envelop theorem, together with the elimination of the Lagrange multipliers $\left(\lambda_{1, t}, \lambda_{2, t}\right)$, and the use of the definition of the utility function, we have:

$$
\begin{aligned}
\frac{\gamma}{W_{t}} & =\beta E_{t}\left[\frac{1}{P_{t+1} C_{1, t+1}}\right] \\
\frac{\gamma}{W_{t}} & =\beta E_{t}\left[\frac{\gamma}{W_{t+1}} R_{t+1}\right] \\
\frac{\theta}{P_{t} C_{2, t}} & =\frac{\gamma}{W_{t}}
\end{aligned}
$$

Conditions (14) and (15) govern the demand for cash money $M_{t+1}^{c}$ and the accumulation of deposits $M_{t+1}^{d}$. (16) gives the optimal demand for credit goods $C_{2, t}$, whereas the demand for cash goods is given by the cash-in-advance constraint

$$
M_{t}^{c}=P_{t} C_{1, t}
$$

\section{A.2 Firms Program}

The representative firm's optimal choices are the solution of the following value function, where $\mathcal{G}_{t}=\left\{N_{t}, K_{t+1}\right\}:$

$$
\mathcal{J}\left(K_{t}, \Omega_{t}\right)=\max _{\mathcal{G}_{t}}\left\{\frac{\gamma}{W_{t}} F_{t}+\beta E_{t} \mathcal{J}\left(K_{t+1}, \Omega_{t+1}\right)\right\}
$$

where the profit flow $F_{t}$ is defined by :

$$
\begin{aligned}
F_{t}= & P_{t}\left(A_{t} K_{t}^{\alpha} N_{t}^{1-\alpha}\right)-P_{t}\left[K_{t+1}-(1-\delta) K_{t}\right] \\
& -R_{t} J_{t} W_{t} N_{t}-\left(1-J_{t}\right) W_{t} N_{t}
\end{aligned}
$$


The discount factor $\beta E_{t}\left[U_{1}\left(C_{1, t+1}, C_{2, t+1}, N_{t+1}\right)\right] / P_{t+1}$ has been substituted by its expression given by (14). The first order conditions of this problem are

$$
\begin{aligned}
0 & =\frac{\gamma}{W_{t}}\left\{P_{t}(1-\alpha) \frac{Y_{t}}{N_{t}}-\left[R_{t} J_{t}+\left(1-J_{t}\right)\right] W_{t}\right\} \\
\frac{\gamma}{W_{t}} P_{t} & =\beta E_{t} \mathcal{J}_{1}\left(K_{t+1}, \Omega_{t+1}\right)
\end{aligned}
$$

The envelop theorem yields

$$
\mathcal{J}_{1}\left(K_{t}, \Omega_{t}\right)=\frac{\gamma}{W_{t}}\left[P_{t} \alpha \frac{Y_{t}}{K_{t}}-(1-\delta)\right]
$$

In equilibrium, equations (18)-(20) can be rewritten as follows

$$
\begin{aligned}
(1-\alpha) \frac{Y_{t}}{N_{t}} & =\left[R_{t} J_{t}+\left(1-J_{t}\right)\right] \frac{W_{t}}{P_{t}} \\
\frac{P_{t} \gamma}{W_{t}} & =\beta E_{t}\left\{\frac{\gamma P_{t+1}}{W_{t+1}}\left[\alpha \frac{Y_{t+1}}{K_{t+1}}-(1-\delta)\right]\right\}
\end{aligned}
$$

Equation (21) determines the labor demand of the firm and (22) governs capital accumulation.

\section{A.3 General Equilibrium}

Since money grows over time, all nominal variables are deflated by the period money stock. Deflated variables are denoted:

$$
p_{t}=\frac{P_{t}}{M_{t}} \quad w_{t}=\frac{W_{t}}{M_{t}} \quad m_{t}^{c}=\frac{M_{t}^{c}}{M_{t}} \quad m_{t}^{d}=\frac{M_{t}^{d}}{M_{t}} \quad x_{t}=\frac{X_{t}}{M_{t}}
$$

The system of equations defining the dynamic general equilibrium of the economy is given by:

$$
\begin{aligned}
m_{t}^{c} & =p_{t} C_{1, t} \\
g_{t} & =J_{t} w_{t} N_{t}+m_{t}^{c} \\
Y_{t} & =A_{t} K_{t}^{\alpha} N_{t}^{1-\alpha} \\
(1-\alpha) \frac{Y_{t}}{N_{t}} & =\left[J_{t} R_{t}+\left(1-J_{t}\right)\right] \frac{w_{t}}{p_{t}} \\
\frac{\theta}{p_{t} C_{2, t}} & =\frac{\gamma}{w_{t}} \\
\frac{\gamma p_{t}}{w_{t}} & =\beta E_{t}\left[\frac{\gamma p_{t+1}}{w_{t+1}}\left(1-\delta+\alpha \frac{Y_{t+1}}{K_{t+1}}\right)\right] \\
g_{t} \frac{\gamma}{w_{t}} & =\beta E_{t}\left[\frac{\gamma}{w_{t+1}} R_{t+1}\right] \\
g_{t} \frac{\gamma}{w_{t}} & =\beta E_{t}\left[\frac{1}{p_{t+1} C_{1, t+1}}\right] \\
K_{t+1} & =(1-\delta) K_{t}+Y_{t}-C_{1, t}-C_{2, t}
\end{aligned}
$$

This dynamic system characterizes the equilibrium stochastic process of the endogenous variables, given the processes of the exogenous variables $\left\{A_{t}, J_{t}, g_{t}\right\}$ and the initial conditions of the state variables. 